\title{
Study of immunoglobulin ' $G$ ' with ultra violet spectroscopy in Duchene muscular dystrophy and Alzheimer's disease
}

\author{
Sanjeev Kumar*, Sweety and Shweta Chaudhary \\ Department of Physics, Medical Physics Research Laboratory, D.A.V. (P.G.) College \\ Muzaffar Nagar - 251001 U.P.(India. \\ *sanjeev1962kumar@yahoo.co.in; *sanjeev1962kumar@rediffmail.com
}

\begin{abstract}
In the present paper, we have studied human IgG in Duchene Muscular Dystrophy (DMD) using ultra violet spectroscopy. A comparison with normal controls is also made. We have found three types of bands in the spectra of IgG of DMD patients and normal healthy controls. First and second band regions cover the ultraviolet behavior of proteins but third band does not show absorbance of proteins because the absorbance intensity greater than $310 \mathrm{~nm}$. Third band does not contain protein without tryptophan. We have to concentrate on the region of two bands below $300 \mathrm{~nm}$. We have first region in the range $200 \mathrm{~nm}$ to $227.38 \mathrm{~nm}$ in DMD patients and $200 \mathrm{~nm}$ to $229.60 \mathrm{~nm}$ in normal controls. Second region starts from $244.40 \mathrm{~nm}$ to $297.70 \mathrm{~nm}$ in patients and $244.40 \mathrm{~nm}$ to $297.70 \mathrm{~nm}$ in controls only. Third band did not show any protein absorbance in all the cases of study. It has been seen that the variation in AD samples is on the decreasing pattern in comparison with healthy controls.
\end{abstract}

Keywords : Immunoglobulin G (IgG), Duchene muscular dystrophy (DMD), Epilepsy (E), Normal (N) , Ultra violet (UV) and Alzheimer's disease (AD).

\section{INTRODUCTION}

One of the most important and exciting advances in modern biochemistry has been the application of spectroscopic method, which measure the emission and absorption of energy of different frequencies by molecules and atoms. Spectroscopic studies of proteins, nucleic acids and other biomolecules are providing many new insights into the structure and dynamic process in these molecules.

Ultra violet visible (UV-Vis) spectroscopy is a different tool of spectroscopy. It is used in the solid state to prove the formation of the complexes [1]. If there is any shifting of the bands can indicate the hydrogen bonding with in the complexes. This technique is used to identify the 
charge transfer reaction. It is very important to note that the results of ultra violet spectroscopy are of relatively little important if not studied infrared spectroscopy along with Nuclear magnetic resonance techniques. On the combined factual view of all the three branches of spectroscopy a valid structural proposal can be made. This is the main reason why the other sections of the work focus on both IR and NMR along with other useful structural determination techniques.

Molecules have the ability to absorb ultraviolet or visible light. Absorption corresponds to excitation of outer electrons in the molecules. These transitions of electrons are important to understand. If a molecule absorbs energy an electron may get promotion from the highest occupied molecular orbital to the lowest unoccupied molecular orbital. The energy differences between electronic levels in most of the molecules vary from 125 to $650 \mathrm{KJ} / \mathrm{mole}$ [2].

It has been established that occupied molecular orbitals with the lowest energy are the $\sigma$ orbitals. If the energy is slightly higher than $\pi$ orbitals come into play a role. Non-bonding orbitals are at still higher energy levels. The highest energy orbitals belong to $\pi^{*}$ and $\sigma^{*}$. These are called unoccupied or ant bonding orbitals. The schematic diagram to represent the electronic transition of the energy levels is given in the Fig. 1.

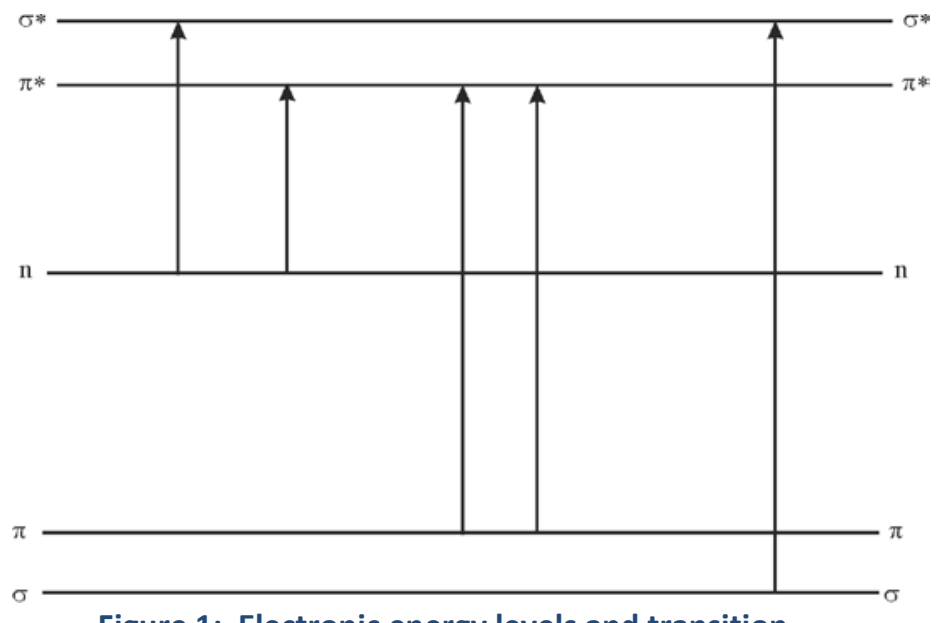

Figure 1: Electronic energy levels and transition

Molecular absorption in the ultraviolet and visible region of the spectrum is dependent on the electronic structure of the molecule. Absorption of energy is quantized. Due to this fact the elevation of electrons from orbitals in the ground state to higher energy orbitals is an excited state. Ultraviolet spectroscopy is limited to conjugated systems for the most part of the electromagnetic spectrum. Ultraviolet spectroscopy provides the facility of recognition of very complexities in molecules. A large portion of a complex molecule may be transparent in the ultraviolet light. A spectrum obtained is similar to that of a much simpler molecule. 
An ultraviolet visible spectrum is a graph of light absorbance verses wavelength in a range of ultraviolet or visible regions. Such type of a spectrum can be produced by a more sophisticated spectrophotometer. Data can be collected one wavelength at a time by simple instruments.

The wavelengths of absorption peaks can be correlated with the types of bands in a given molecule. The wavelength is valuable in determining the functional groups within a molecule. Ultraviolet and visible absorption is not a specific test for any given compound. The nature of the solvent, the $\mathrm{pH}$ of solution, temperature, high electrolyte concentrations, and the presence of interfering substance can influences the absorption spectra of compounds. The variations can be made in width of the slit for band within the spectrophotometer.

Ultraviolet visible spectroscopy is routinely used in the quantitative determination of solutions of transition metal ions and highly conjugated organic compounds.

Solutions of transition metal ions can be coloured. These can absorb visible light. The ' $d$ ' electrons within the metal atoms can be excited from one electronic state to another state. The colour of metal ion solutions is strongly affected by the presence of other species. These may be certain anions or ligands. Organic compounds with a high degree of conjugation also absorb light in the ultraviolet or visible regions of electromagnetic spectrum. Solvents for these determinations are generally water; it can be used for water soluble compounds. Ethanol can be used for organic soluble compounds. The radiations which move with the speed of light are called "electromagnetic radiations". Radiation vibrates perpendicular to the direction of propagation with wave motion.

It is broken completely into the several portions called as electromagnetic (EM) spectrum. Different regions of this spectrum provide different kinds of information as a result of interactions. Light may be considered to have both waved and particle character shown in Fig. 2.

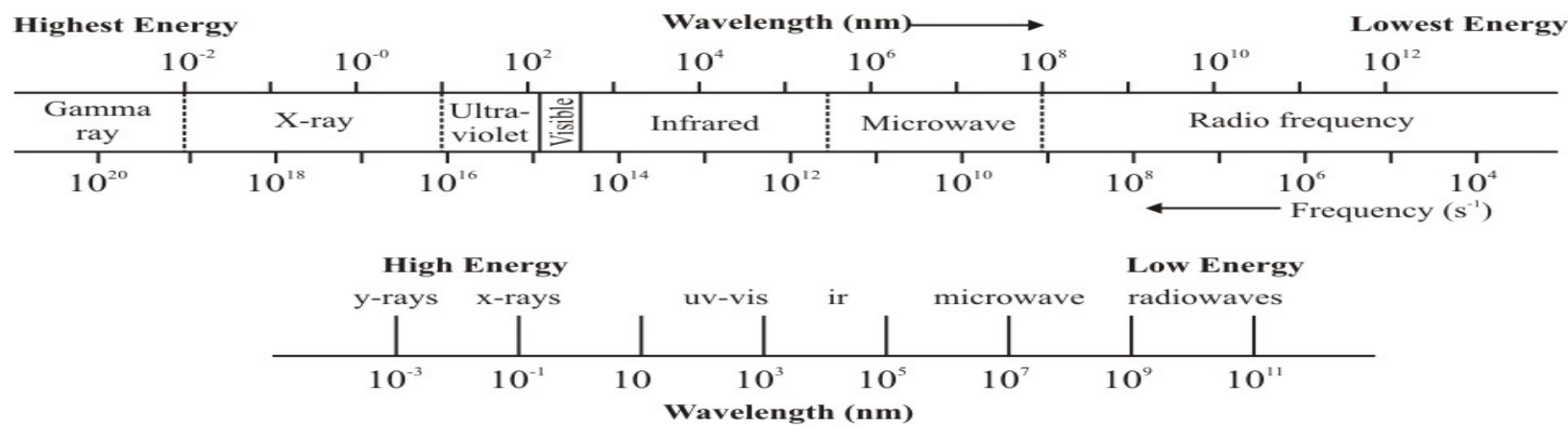

Figure 2: Energy spectrum of different wavelengths to show the different regions.

The part of the e.m. radiation spectrum with the visible light is most familiar to us. This is the small portion of all the possible types. Molecular absorption spectroscopy in the ultraviolet and visible is concerned with the measured absorption of radiation in its passage through a solid 
liquid or a gas. The wave length region is used for this type of spectroscopy is from $190 \mathrm{~nm}$ to $1000 \mathrm{~nm}$. The absorbing medium is kept at room temperature. Ultraviolet and visible spectroscopy is used to measure the multiple bonds or aromatic conjugation within the molecule. UV-Vis region is subdivided further as vacuum UV (100 nm to $200 \mathrm{~nm}$ ), near UV (200 $\mathrm{nm}$ to $400 \mathrm{~nm}$ ) and visible region (400 nm to $750 \mathrm{~nm}$ ). Vacuum UV is called because molecules of air absorb radiations in this region. Molecule absorption spectra are more meaningfully considered as a function of wave number $\left(\mathrm{Cm}^{-1}\right)$. We use wave length $(\mathrm{nm})$ to measure the quantity of absorption.

UV-Vis spectroscopy involves the absorption of UV and visible light by the molecule causing the promotion of an electron from ground electronic state to an excited electronic state of the transition. Absorption of this high energy light causes electronic excitation. The easily accessible part of the region is from $200 \mathrm{~nm}$ to $800 \mathrm{~nm}$. This shows absorption only if conjugated $\pi$-electron systems are present. Ultra violet radiation having wavelength less than $200 \mathrm{~nm}$ is more difficult to handle. The energies are sufficient to promote or excite a molecular electron to a higher energy orbital. Ultra-violet region is only a small part of the electromagnetic spectrum and it extends from $190 \mathrm{~nm}$ to $300 \mathrm{~nm}$. We are interested in the spectrum, which obtained when ultra-violet light passes through medium and not in the source spectrum. The interaction of ultraviolet radiations with matter may result either in the emission or in the absorption spectrum. UV radiations excite the transparent substance from the lower to higher energy state via electronic transitions. The transitions induced by ultra violet are not common to all electronic structures; in fact these take place in conjugated systems. We are in a position to recognize the characteristic groups because the UV spectra are highly sensitive to environmental factors in biological macromolecules. As the energies involved in electronic spectra are large, these are associated with changes in rotational and vibrational states, which blur the observed spectrum, rendering it characterless in liquids. However, even this highly characteristic of a particular molecular group lies both in its frequency and intensity.

The spectra have the absorption peak position and the intensity of the peak. We can express the peak position in wave length $(\mathrm{nm})$, frequency $(\mathrm{Hz})$ or wave number $\left(\mathrm{Cm}^{-1}\right)$.

The intensity is dependent on the interaction probability and hence the dipole moment of transition. This parameter depends on the electronic charge distribution in transition. Low probability transitions are forbidden.

The polarity of the exited state also affects the intensity. Light absorption laws in transparent medium were formulated by Lambert [3] and the intensity of transmitted light was given by

$$
I=I_{0} e^{-\alpha \ell}
$$


where $\mathrm{I}_{\mathrm{o}}$ is the intensity of the incident light, the characteristic coefficient of absorption for the medium and $l$ is thickness of the absorbing medium. We can calculate the Bunson-Rosioe extinction coefficient $(\mathrm{K})$ by the formula

$$
\begin{gathered}
K=\left[\log _{10}\left(\frac{I_{0}}{I}\right)\right] \frac{1}{\ell}, \\
K \ell=\log _{10}\left(\frac{\mathrm{I}_{0}}{\mathrm{I}}\right), \\
\left(\log _{\mathrm{e}} 10\right)(\mathrm{K} \ell)=\left[\log _{10}\left(\frac{\mathrm{I}_{0}}{\mathrm{I}}\right)\right]\left(\log _{\mathrm{e}} 10\right), \\
2.3026 \mathrm{~K} \ell=\log _{\mathrm{e}}\left(\frac{\mathrm{I}_{0}}{\mathrm{I}}\right), \\
\mathrm{e}^{2.3026} \mathrm{~K} \ell=\frac{\mathrm{I}_{0}}{\mathrm{I}}, \\
\mathrm{I}=\mathrm{I}_{0} \mathrm{e}^{-2.3026 \mathrm{KI}}
\end{gathered}
$$

Comparing (1) and (3), we get

$$
\alpha=2.3026 \mathrm{~K}
$$

The intensity of transmitted light is given by Lambert - Beer Law [3],

$$
\begin{gathered}
\frac{I}{I_{0}}=e^{-K C \ell} \\
\text { or } \quad K C \ell=\log _{e}\left(\frac{\mathrm{I}_{0}}{\mathrm{I}}\right)=\mathrm{A},
\end{gathered}
$$

The absorbing molecules having concentration C. $\mathrm{K}$ is constant characteristic of the solute and $I$ is the solution path length. $A$ is known as absorbance or absorptivity.

When the constituents of the absorbing molecule are unknown, intensity is expressed as the absorption by the solution of $1 \mathrm{gm} / 100 \mathrm{ml}$ concentration and 1 centimeter path length of the sample $\left(E_{1 \mathrm{~cm}}^{1 \%}\right.$ or $\left.A_{1 \mathrm{~cm}}^{1 \%}\right)$

$$
\text { Thus } \quad\left(E_{1 c m}^{1 \%}=\frac{A}{C \ell}\right)
$$

The corresponding energy is given below 


$$
\mathrm{E}\left(\frac{\mathrm{kcal}}{\mathrm{mol}}\right)=\mathrm{Nhv}=\frac{28.587}{\lambda(\mathrm{nm}) \times 10^{3}}
$$

The total energy of molecule is given by

$$
E=E_{e}+E_{v}+E_{r},
$$

where $E_{e}$ is the electronic energy, $E_{v}$ the vibrational energy and $E_{r}$ the rotational energy.

Transitions of electrons take place from filled molecular orbits in ground state involving bonding $(\sigma$ and $\pi$ ) or non bonding $(n)$ orbits (electrons), to higher energy involving the antibonding $\sigma^{*}$ or $\pi^{*}$ orbitals. These remain empty in an unexcited state. It is customary to discuss and to describe the intensities of absorption bands in terms of molar absorptivities $\in_{\max }$ (molar extinction coefficients). The coefficients can be obtained from the determination of the wavelength of maximum absorption. Accurate measurement of the absorbance at this one wavelength can provide these coefficients. $\epsilon_{\max }$ is not directly related to any quantity.

Changes in the energies accompany the changes in electronic energy and give rise to the familiar band spectra. A single electronic transition comprises many individual lines (bands), and the quantity, i.e., total energy transferred should be sum of the contributions from all these lines (bands).

The quantity of interest in ultraviolet spectroscopy is not $\epsilon_{\max }$ but it is the integrated (absolute) intensity (I). This is equal to the area under the absorption curve. Ultraviolet spectra rarely contain isolated bands, and we must extrapolate the band to the abscissa in arbitrary manner.

Now, experimental integrated intensity is mathematically defined by the integral

$$
\mathrm{I}=\int \in \mathrm{d} v
$$

In UV region, strongly overlapping bands are frequently encountered. Evaluation of the integrated intensity of such bands requires analysis into separate bands.

\section{Calculation of Absorption Intensity}

Calculation of absolute intensity of an absorption (or emission) bands is not difficult. Mulliken [4] has shown probabilities of emission (A) and absorption (B) between two electronic states from initial (i) to final ( $f$ ) by the relation

$$
\begin{aligned}
A_{\text {if }} & =\left(64 \pi^{4} v^{3} e^{2} / 3 h\right) G_{f} D_{\text {if }} \\
B_{i f} & =\left(8 \pi^{3} e^{2} / 3 h^{2} c\right) G_{f} D_{i f}
\end{aligned}
$$


where, $\mathrm{e}$ is the electronic charge of electron, $\mathrm{h}$ is Planck's constant, $\mathrm{c}$ is the velocity of light, $v$ is the frequency of emission, $G_{f}$ is the statistical weight of the final state, $D_{\text {if }}$ is the dipole strength.

$B_{\text {if }}$ can be transformed into a measure of intensity, the oscillator strength $f$, which is given by

$$
\mathrm{f}=\left(\frac{8 \pi^{2} \mathrm{mc}}{3 \mathrm{~h}}\right) \mathrm{G}_{\mathrm{f}} v \mathrm{D}_{\text {if }}=1.096 \times 10^{11} \mathrm{G}_{\mathrm{f}} v \mathrm{D}_{\text {if }}
$$

and is related to the absolute intensity

$$
f=0.102\left(\mathrm{mc}^{2} / \mathrm{N} \pi \mathrm{e}^{2}\right) \int \in \mathrm{d} v=4.315 \times 10^{-9} \int \in \mathrm{d} v
$$

where $\mathrm{m}$ is the mass of the electron, $\mathrm{N}$ is Avogadro's number, $\in$ is the molar absorption coefficient, $G_{f}$ is considered as unity.

The dipole strength (D) is proportional to the intensity and is given by the relation

$$
I^{2} \alpha D^{2}=\int \psi_{i} M \psi_{f} d \tau
$$

$\psi_{\mathrm{i}}$ and $\psi_{\mathrm{f}}$ are the total wave functions of the initial and final states of the molecule respectively, $d \tau$ are represents the product of the volume elements in the coordinates of all the nuclei and electrons, $\overline{\mathrm{M}}$ is called dipole moment vector.

According to quantum mechanics, desired average can be obtained as

$$
\int \psi_{\mathrm{i}} \sum \mathrm{er} \psi_{\mathrm{i}} \mathrm{dT}=\left(\psi_{\mathrm{i}} \mathrm{M} \psi_{\mathrm{f}} \mathrm{dT}\right)
$$

where, $\overline{\mathrm{M}}=\Sigma \mathrm{e} \overline{\mathrm{r}}$ is called the dipole moment vector.

Now, $\overline{\mathrm{M}}$ in 3-Cartesian coordinates axes is given by the relation as described below

$$
\mathrm{M}^{2}=\mathrm{M}_{\mathrm{x}}^{2}+\mathrm{M}_{\mathrm{y}}^{2}+\mathrm{M}_{\mathrm{z}}^{2}
$$

$D^{2}$ can be given by the following relation

$$
\mathrm{D}^{2}=\int \psi_{\mathrm{i}} \mathrm{M} \psi_{\mathrm{f}} \mathrm{dT}
$$

where $\psi_{\mathrm{i}}$ and $\psi_{\mathrm{f}}$ are the total electronic wave functions of the initial and final states, $\mathrm{d} \tau$ is the product of the volume elements in terms of the coordinates of all the electrons. 
If the spectral shape of a ligand spectrum does not change but the magnitude changes in such a way that it is proportional to the concentration of bound ligand, then the spectral data can be utilized to estimate the equilibrium binding constant, K. The ligands are binding in one binding mode or in constant proportions in more than one mode.

If we consider the equilibrium

$$
\mathrm{L}_{\mathrm{b}} \stackrel{\mathrm{k}}{\rightleftarrows} \mathrm{L}_{\mathrm{f}}+\mathrm{S}_{\mathrm{f}}
$$

where $L_{b}$ is a bound ligand and $L_{f}$ is a free ligand, $S_{f}$ is a free site.

If we treat a macromolecule, which is a series of binding sites of $\mathrm{n}$ residues in size, then the total site concentration is given by the following relation

$$
\frac{[\mathrm{M}]}{\mathrm{n}}=\mathrm{S}_{\text {tot }}
$$

Here, $[\mathrm{M}]$ is the concentration of the macromolecule residue.

It has been reported that for proteins and sometimes preferable to take as concentration of molecules rather than residues.

$$
\mathrm{S}_{\text {tot }}=\mathrm{n}^{\prime}[\mathrm{M}]
$$

Here, $n^{\prime}$ is the number of binding sites per protein.

We have the calculation for $\mathrm{k}$ which is given below

$$
\mathrm{k}=\frac{\mathrm{nC}_{\mathrm{b}}}{\mathrm{C}_{\mathrm{f}}[\mathrm{M}]}
$$

Ultraviolet spectroscopy can be used for multi component analysis of mixture consisting of $\mathrm{n}$ absorbing analytes is possible provided the Beer-Lambert Law is valid and holds, by measuring the absorbance at $k$ suitable wavelengths with $k>n$, For each wavelength $\lambda_{a}$. This ' $a$ ' can have the values $1,2, \ldots \ldots . . . \mathrm{k}-1, \mathrm{k}$.

Total absorbance is given by the relation

$$
\mathrm{A}\left(\lambda_{\mathrm{a}}\right)=\mathrm{b} \sum_{\mathrm{i}=1}^{\mathrm{n}} \varepsilon_{\mathrm{i}}\left(\lambda_{\mathrm{a}}\right) \mathrm{C}_{\mathrm{i}}
$$

where $\varepsilon_{i}\left(\lambda_{a}\right)$ is the molar (decadic) absorption coefficient of analyte $i$ at the wavelength $\lambda$.

$C_{i}$ is its molar concentration.

The ratio $A\left(\lambda_{a}\right) / b$ is called linear decadic absorption coefficient. This quantity is also called linear absorbance. 
The concentrations of the $\mathrm{n}$ analytes may then be calculated from $\mathrm{k}$ simultaneously equations.

The use of derivative spectroscopy decreases the signal to noise ratio. It can improve the detection of a sharp band in a broad back ground, or a narrow shoulder on a broad band. Gradual changes in spectral back ground or source flux will be less pronounced in derivative spectroscopy.

Derivative spectra are generally obtained by digital differentiation or by wavelength modulation of the radiation entering the sample cell. The wavelength modulation interval has to be much less than the band width of any absorption band in the spectrum.

The derivative spectrum in terms of wave number can be calculated from the spectrum in terms of wavelength by

$$
\begin{aligned}
& \frac{d A(\bar{v})}{d \bar{v}}=\left(-\lambda^{2}\right) \frac{d A(\lambda)}{d_{\lambda}} \\
& \frac{d^{2} A(\bar{v})}{d \bar{\nu}^{2}}=\left(\lambda^{4}\right) \frac{d^{2} A(\lambda)}{d \lambda^{2}}+2 \lambda^{3} \frac{d A(\lambda)}{d \lambda}
\end{aligned}
$$

The first and second derivatives of the Beer' - Lambert Law are. If $\frac{d \phi_{0}}{d \bar{v}}=0$ then we can write these derivatives as

$$
\begin{aligned}
& \frac{\frac{d \phi_{t}}{d \bar{v}}}{\phi_{t}}=-2.303 \mathrm{c} \mathrm{b} \frac{\mathrm{d} \varepsilon}{\mathrm{d} \bar{v}} \\
& \frac{\frac{\mathrm{d}^{2} \phi_{\mathrm{t}}}{\mathrm{d}^{2}}}{\phi_{\mathrm{t}}}=\left[2.303 \mathrm{cb} \frac{\mathrm{d} \varepsilon}{\mathrm{d} \bar{v}}\right]^{2}-2.303 \mathrm{c} \mathrm{b} \frac{\mathrm{d}^{2} \varepsilon}{\mathrm{d} \bar{v}^{2}}
\end{aligned}
$$

Second derivative spectra are predominantly used in quantitative analysis.

Molecular absorption spectroscopy in the ultra violet and visible is concerned with the measured absorption of radiation in its passage through a gas, liquid or a solid. Ultra violet spectroscopy allows for the determination of the concentration of protein in a sample as the absorbance at $280 \mathrm{~nm}$ and it is directly proportional to the concentration of protein. The protein sample has tryptophan or tyrosine content, which absorb at $280 \mathrm{~nm}$. Determination of protein concentration can be done by the absorbance at $205 \mathrm{~nm}$. Peptide bonds are analyzed directly by the using a method of Scoopes [5]. 
Jagger [6] has reported that the important molecular components of proteins that are expected to absorb ultra violet are the aromatic amino acids and peptide bond. Tryptophan and tyrosine are the major components, which absorb ultra violet above $250 \mathrm{~nm}$. Phenylalanine, cystine are also important components because most of the other amino acids do not absorb in this region. These two components may be major absorbers in a protein with low tryptophan tyrosine content. Disulfide bonds are very crucial structures. Their presence increases the UV liability of proteins. Peptide bond $(-\mathrm{CONH}-)$ has some double bond character. It is a relatively weak absorber and is only important below $240 \mathrm{~nm}$. A peptide bond for every amino acid residue in a protein makes its contribution to protein absorption below $240 \mathrm{~nm}$.

There is an interaction in a protein among amino acids. The total absorbancy of a protein solution is quite similar to the sum of the absorbencies of solutions of the component amino acids. Proteins usually exhibit an absorption peak around $280 \mathrm{~nm}$. Scopes, R. K. [7] has measured proteins at $205 \mathrm{~nm}$ and given a formula regarding the average absorbance due to tryptophan and tyrosine at $205 \mathrm{~nm}$ is given here. as

$$
\left[3.6+\left(\frac{4.6-3.6}{4}\right)\right] \times A_{280}=3.85 \times A_{280}
$$

We can write an expression

$$
€_{205}^{1 \mathrm{mg} / \mathrm{ml}}=\mathrm{c}+3.85 \times €_{280}^{1 \mathrm{mg} / \mathrm{ml}}
$$

$\mathrm{C}$ is the extinction coefficient due to the polypeptide chain in its native configuration, plus contributions from phenylalanine, histidine and other residue side chains but excluding tyrosine and tryptophan.

For a protein solution of unknown concentrations, values of the absorbance. $A_{280}$ and $A_{205}$ are noted. The expression $\in_{205}^{1 \mathrm{mg} / \mathrm{ml}}$ can be replaced by $\in_{205}^{1 \mathrm{mg} / \mathrm{ml}} \times \mathrm{A}_{280} / \mathrm{A}_{250}$.

We can write two possibilities of approxmamation as

$$
\begin{aligned}
& \in_{205}^{1 \mathrm{mg} / \mathrm{ml}}=31 \\
& \in_{205}^{1 \mathrm{mg} / \mathrm{ml}}=\mathrm{C}+120 \times\left(\mathrm{A}_{280} / \mathrm{A}_{250}\right)
\end{aligned}
$$

and if we rearrange eq ${ }^{n}(28)$ as 


$$
\in_{205}^{1 \mathrm{mg} / \mathrm{ml}}=\frac{\mathrm{C}}{1-3.85 \times\left(\mathrm{A}_{280} / \mathrm{A}_{205}\right)}
$$

If we substitute $C=27.0$

We can have the best values as

$$
\begin{aligned}
& \in^{105}{ }^{1 \mathrm{mg} / \mathrm{ml}}=27.0+120 \times\left(\mathrm{A}_{280} / \mathrm{A}_{205}\right) \\
& \in^{105}=\frac{27.0}{1-3.85 \times\left(\mathrm{A}_{280} / \mathrm{A}_{205}\right)}
\end{aligned}
$$

Perkampus [8] has provided some of the features of bond analysis with the Gaussian and Lorentzian functions. The bands to be separated in most of the cases can be approximated by Gaussian curves and the extinction coefficient or absorbance can be written here as.

$$
\mathrm{A}=\mathrm{A}_{\max } \cdot \bar{e}^{\left\{B\left(\bar{v}_{0}-\bar{v}\right)^{2}\right\}}
$$

$\overline{\mathrm{v}}_{0}$ is the wave number at the band maximum.

The parameter $B$ is connected to the full width at half the maximum intensity of the band by the following $\mathrm{eq}^{\mathrm{n}}$.

$$
\mathrm{B}=\frac{4 \log _{2}}{\Delta \bar{v}_{1 / 2}^{2}}
$$

$\mathrm{Eq}^{\mathrm{n}} \mathrm{s}(34)$ and (35) can be written as

$$
\left[\log \left(\frac{A_{\max }}{A}\right)\right]^{1 / 2}=(B \bar{v})^{1 / 2}-\left(B \overline{v_{0}}\right)^{1 / 2}
$$

$\mathrm{Eq}^{\mathrm{n}}(36)$ is the basis for a linear regression for fitting the theoretical to experimental curve.

\section{REVIEW OF THE LITERATURE}

The application of UV absorption spectroscopic technique for the examination of the concentration of protein molecules has undergone significant change during the past couple of years. Changes in conformation with altered temperature or with the addition of organic molecules to an aqueous solvent medium, are usually associated with positional shifts and 
intensity changes in ultra-violet absorption bands. These variations can be explained on the basis of the energy level transitions and empirical correlations with information obtained by other methods.

Proteins interact with ultra violet light with a consequent absorption of energy giving rise to absorption spectrum [8]. Not all molecules are found to exhibit this absorption. This phenomenon is confined to the molecules with double bonds and longer wavelength to conjugated bonds. The energy absorbed by the molecule causes electronic transition from ground state to one of the molecular excited states involving an electron a $\pi$ orbital or a non bonding $p$-type orbital into a higher anti-bonding $\pi^{*}$-orbital. Thus the transition between the ground state of entire system and the excited state of the chromosphere proves quite helpful in understanding the structure of proteins. The absorption spectrum in ultra violet region is influenced by a number of factors including the state of bonding and nature of the bonds involved. The shift in the position of absorption maxima and change in the area under the absorption curve help in the recognition of a characteristic group or its environments. The excitation of electrons in the frequency above $50,000 \mathrm{~cm}^{-1}$ has been used to determine the conformation of peptide chains which has characteristic absorption maxima at $185 \mathrm{~nm}$.

Many properties of proteins including their primary structure, modification of sequence of amino acids in polypeptide chains and covalently attached prosthetic groups influencing the nature and function of proteins have been studied in the past by using this technique.

This study also took into consideration the question of inter atomic distances and the bond angle from the shift in absorption peaks on their intensities. The plasma proteins in general give absorption bands between $200 \mathrm{~nm}$ to $400 \mathrm{~nm}$. Aromatic proteins absorb in the range $260 \mathrm{~nm}$ to $280 \mathrm{~nm}$. The $280 \mathrm{~nm}$ absorption is due to tryptophan and tyrosine residues in the aromatic proteins. Phenylalanine absorbs at slightly lower wave length $\sim 255 \mathrm{~nm}$. The free amino acid contents of plasma show concentration of phenylalanine as $0.95 \mathrm{mg} / 100 \mathrm{ml}$, tyrosine as $0.91 \mathrm{mg} / 100 \mathrm{ml}$ and tryptophan as $0.98 \mathrm{mg} / 100 \mathrm{ml}$ of plasma.

Most of the previous investigations of ultra-violet spectra of protein measured in the region ranges from $250 \mathrm{~nm}$ to $300 \mathrm{~nm}$. In this region absorption is due almost entirely to the aromatic side chains of tryptophan, tyrosine and phenylalanine. The stronger absorption bands of these side chains between $190 \mathrm{~nm}$ to $240 \mathrm{~nm}$, not studied rigorously till now. One can attribute this to technical problems and still more because of the overlapping absorption in this region from histidine, methionine, cystine and ionized cystine and the long wave length end of the absorption due to the peptide bond itself.

Absorption bands located below $200 \mathrm{~nm}$ have been of great interest. Absorption band of the peptide linkage is centered near $190 \mathrm{~nm}$. The transition from a helix to a random coil is associated with significant increase of ultra violet absorption in this region. The work of 
Rosenheck and Doty [9] has given importance to the absorption studies in the ultra violet region. The main factor for this lies in the strong connection between the ultra violet absorption bands and the optical rotatory dispersion (ORD) changes associated with the helix coil transition. The intermediate region of $200 \mathrm{~nm}$ to $250 \mathrm{~nm}$ has been studied in some of earlier publications [10,11]. Difference spectra in neutral and acid solutions of several proteins exhibit a significant line near $235 \mathrm{~nm}$. This peak is higher compared to the signals due to tyrosine residues near $278 \mathrm{~nm}$ to $287 \mathrm{~nm}$ or those due to tryptophan at slightly larger wave lengths.

So far as the structure of native globular proteins is concerned, the amino acids side chains may emerge on the outer side towards the solvent from the main peptide chain or may be folded into the interior of the molecule and enclosed by surrounding groups of the protein itself. Native globular proteins are immunoglobulins such as IgG, IgA, IgM, IgD and IgE. Intermediate situations may also present. An amino acid side chain is likely to be partly covered near the surface of the molecule but flexible enough to appear out occasionally and have interactions with the surrounding solvent. Some proteins are also likely to have water molecules trapped in the interior, so that internal groups may still have association with water.

There is a possibility of some sort of fissures or crevices at the surface of the protein molecule. Small solvent molecules can go through these fissures. The amino acids composition of globulin in the decreasing order or proportion is given below:
(1) Leucine
(2) Valine
(3)
Aspartic acid
(4) Alanine
(5) Lysine
(6) Histidine
(7)
Phenylalanine (8)
Glutamic acid
(9) Theonine
(10) Proline
Glycine
Serine
(13) Tyrosine
(14) Arginine
(15) Tryptophan
(16)
Methionine

\section{Cysteine}

Jiang et. al. [12] studied this spectroscopy technique for the protein back bone transitions in aqueous solution. They have made some calculations to simulate and backbone transitions of protein. One can find such type of transitions in the region $180 \mathrm{~nm}$ to $220 \mathrm{~nm}$. These findings are very sensitive and provide a probe for secondary structure of proteins. They have characterized fine structure of UV spectra accurately for the identification of secondary structure of proteins.

Amoldus et. al. [13] have studied the thermal stability of immunoglobulin and measured the protein concentration at $280 \mathrm{~nm}$. The study of the structure of immunoglobulins in detail reveals that these proteins are composed of four polypeptide chains which are connected by disulphide bonds and non-covalent forces. The four polypeptide chains are grouped together in different fragments, two identical $F_{a b}$ segments and one $F_{c}$ segment forming a $Y$ shaped conformation. The antigen binding sites are located on the far ends of the $F_{a b}$ segments. The $F_{a b}$ 
segments are linked to the $F_{c}$ by the hinge region, which varies in length and flexibility in the different antibody classes and isotypes.

Motrescu et. al. [14] have studied spectrophotometric analysis of the blood plasma for different mammals to study and establish a correlation between protein concentration and their absorbance in the ultraviolet region. Protein absorbance band at $280 \mathrm{~nm}$ determines the characteristic spectrum of the blood plasma and the absorption maximum strongly depends on the blood plasma protein concentration.

Kanagathara, N. et. al. [15] have applied UV-visible spectral study on normal blood samples and found that there is a linear relationship between the protein content and the maximum absorption in the ultraviolet region. A band at $280 \mathrm{~nm}$ helps in determining the characteristic spectrum of the blood plasma. They have also reported that the absorption spectrum of the diseased samples of blood show same changes from normal blood sample. It may help us and treated as an evidence for the manifestation of the disease.

Gunasekaran et. al. [16] have also studied the ultraviolet spectroscopy on normal and jaundice blood samples and reported their findings as proteins in the sera absorb strongly at $280 \mathrm{~nm}$. It is due to amino acids like tyrosine and tryptophan. The amide backbone of the proteins in the blood shows a band at $210 \mathrm{~nm}[14]$.

Yuette et. al. [17] have used this technique to characterize and differentiate the types of blood. Yuette et. al. [18] have also used the spectroscopy for the quantitative investigation of platelet quality. The optical properties for isolated platelets, platelet rich plasma and leukopleted platelet rich plasma have also been determined.

Akihisa [19] used this technique for the characterization of red blood cells. A Successful simulation of experimental red cell spectra, which contain various amounts of hemoglobin, were also carried out. A quantitative interpretation of the red blood cell spectra was also achieved in context of corpuscular hemoglobin concentration, corpuscular volume, and cell count.

A very important class of proteins that conform to a common submit structures are immunoglobulins. These molecules have domains which are structurally independent, compact globular regions consisting of continuous stretches of the polypeptide chain of hundred amino acids long, with a characteristic fold. This fold contains two $\beta$-sheets and essentially no $\alpha$ helices. These globular protein structures have a unique feature regarding non-polar residues which are sequestered into a core.They avoid contact with water at this stage. Immunoglobulins or antibodies show a very strong structure function relation in the different domains. Due to this property these molecules have an excellent system for various diagnostic tests. The domains of the antibodies with a high specificity to bind the analyte assure that these immunoglobulins can be used for a reliable and fast determination of low concentrations of 
analyte. Other domains of immunoglobulin promote protein binding to a surface in the proper orientation. Its binding sites are easily accessible to the antigen.

Welhelm et. al. [20] have studied ultraviolet absorption spectra of blood serum and certain amino acids and reported that the absorption band around $280 \mathrm{~nm}$ of blood serum was due to the presence of proteins. They were mainly the tyrosine and tryptophan constituents of the proteins are responsible for a nice and clear band. A mixture of tyrosine, tryptophan, phenylalanine, cystine, glycine, leucine and glutamic acid in proportion indicated by analysis of blood serum (albumin and globulin) gives the ultraviolet visible spectra.

Malvin [21] has studied ultraviolet absorption spectra of certain physiological fluids, such as human bile, saliva, pericardial fluid, uric acid, urine, albumin, pseudo globulin euglobulin and $\mathrm{O}-\mathrm{O}$ blood serum and plotted some graphs, which are valuable to the clinician and researchers. Edward et. al. [22] have studied the middle ultraviolet spectra of proteins and found that major absorption band of the aromatic compound was due to a $\pi \rightarrow \pi^{*}$ transition. Minor transition was involved in tyrosine spectrum.

Alastair et. al. [23] have determined protein by UV absorption and found that absorption of radiation in the near UV by proteins depends on the tyrosine and tryptophan content and to a very small extent on the amount of phenylaline and disulfide bands. They have also reported that the extinction of nucleic acid in the $280 \mathrm{~nm}$ region may be as much as ten times that of protein at their same wavelength. Nucleic acid in small percentage can influence the absorption.

Yong et. al. [24] have studied the effect of ultraviolet irradiation on molecular properties and immunoglobulin production regular activity of $\beta$-lactoglobin and found that ultraviolet irradiation is effective for altercation of molecular properties and anti-genicities of $\beta$ lactoglobulin. Low allergenic foods may be prepared with the help of such types of treatment.

Henry et. al. [26] have studied application of ultraviolet absorption spectroscopy to the analysis of biopharmaceuticals. They have suggested that the non-destructive technique depends on contributions from ultraviolet absorption of aromatic amino acids, cystine and light scattering. This technique can be used for determination of concentration and detection of impurities as well as assessment of aggregation state.

Mc Crathy et. al. [27] have studied this spectroscopy on IgG aggregate formation and found that few changes were observed in treated IgG. These changes remained un-aggregated but so many significant size dependent changes were also seen in aggregated IgG.

Edelhoch [28] has studied spectroscopic determination of tryptophan and tyrosine in proteins and presented a rapid method for the determination of tryptophan in proteins and it was based on absorbance measurements at $288 \mathrm{~nm}$ and $280 \mathrm{~nm}$. of the protein. 
Mansor et. al. [29] have studied FTIR and UV-Vis study of chemically engineered biomaterial surfaces for protein immobilization. They suggested that proteins have a very particular chain configurations and conformations that promote high levels of specificity during chemical interactions. They have also studied the phonomenous of protein immobilization onto biomaterial with chemically engineered surface. They have succeeded to put forward the views such that all the surface modeled material has shown acute hypoglycemic peak response associated with the insulin bioactivity.

Mirian et. al. [30] have studied ultraviolet spectroscopy of hemes in electron carrier Ctype cytrochromes and its model compounds and found that some of the compounds have shown their spectra at different wavelength such as cytrochrome C at 406 and $530 \mathrm{~nm}$. Cytrochromes C-557 at 409, $525 \mathrm{~nm}$, Cytochrane C has shown two peaks at 408 and $530 \mathrm{~nm}$. MP-9 at 395, 507 and $622 \mathrm{~nm}$. Hemin has shown two peaks at 383 and $613 \mathrm{~nm}$. These compounds were tested at $7.2 \mathrm{pH}$.

Sanii et. al. [31] have studied UV-Visible spectroscopy of the native membrane and the structure of retinal and found those two bands for protein bacterierhodospin at $280 \mathrm{~nm}$ and at $570 \mathrm{~nm}$. The $280 \mathrm{~nm}$ absorption band is due to the $\pi \rightarrow \pi^{*}$ transition of the tyrosine and tryptophan amino acid.

\section{MATERIAL AND METHODS}

The blood samples of Alzheimer's disease patients were collected from the Department of Neurology, Safdarjang Hospital, New Delhi. Twenty milliliters freshly drawn blood from each patient was collected in clean and dry test tube without any anti-coagulant. The test tube was kept for 45 minutes at room temperature $\left(22 \pm 2^{\circ} \mathrm{C}\right)$ for the formation of clot. Sera of different patients were separated by centrifugation at 1500 r.p.m. upto 15 minutes and were collected in screw capped test tubes. IgG sample were prepared on protein A-Sepharose method [32].

The IgG binding properties of protein $A$, make affinity chromatography with protein Asepharose $C L-4 B$ a very simple method for preparing IgG. 1.5 g protein-A sepharose $C L-4 B$ was swollen in $10 \mathrm{ml}$ phosphate buffered saline (PBS) for 1 hour at room temperature and then packed into a small chromatography column. $10 \mathrm{ml}$ human serum was diluted with an equal volume of PBS. The serum was filtered through the column at a flow rate of $30 \mathrm{ml} / \mathrm{h}$. Washing was done through unbound protein with PBS. Until no more protein left the column (the protein was monitored with a UV flow cell).

The bound IgG was eluted with glycine-HCL buffer having a $\mathrm{pH}$ value of 2.8. The $\mathrm{pH}$ of purified IgG solution was titrated to near neutrality with $\mathrm{NaOH}$ and dialyzed against PBS. The column was regenerated by washing with 2 column bed volume of PBS. The column was stored at $4^{\circ} \mathrm{C}$. 
The protein A content of the swollen gel is $2 \mathrm{mg} / \mathrm{ml}$ and the binding capacity for human IgG is approximately $25 \mathrm{mg} / \mathrm{ml}$ of packed gel. As binding of protein A to IgG involves tyrosine residues on the protein $A$ glycosyl tyrosine $(0.1 \mathrm{M}$ in $2 \mathrm{NaCl})$ can be used to elude the IgG rather than the glycine $-\mathrm{HCl}$ buffer.

The ultra-violet spectra of the IgG extracted from normal person and Alzheimer's disease patients were recorded on Shimadzu UV visible recording Spectrophotometer UV-260. Normal saline was used as a reference. Block diagram of ultraviolet spectrophotometer is shown in Fig. 3

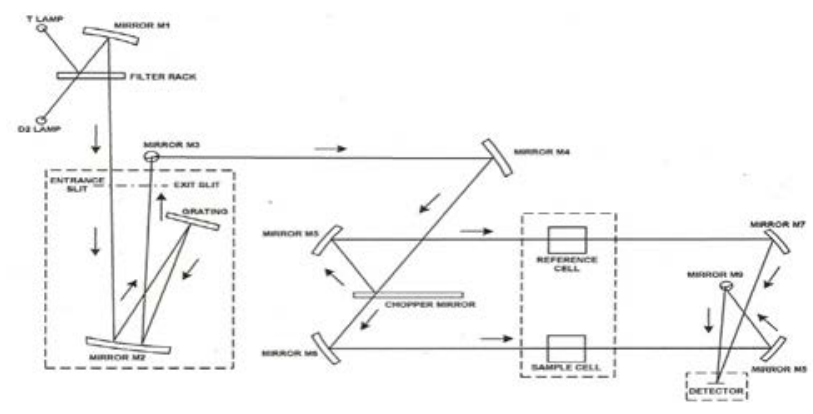

Figure 3: Block diagram of ultraviolet spectrophotometer

\section{RESULTS}

Ultraviolet absorption spectra of Alzheimer's disease patients were recorded and compared with normal healthy controls. We observe peaks at different wavelength in all samples. A comparative detail of the work is given in Table-1. Typical ultra violet spectra of DMD , $A D$ and control person are given in Fig.4 to Fig.6.

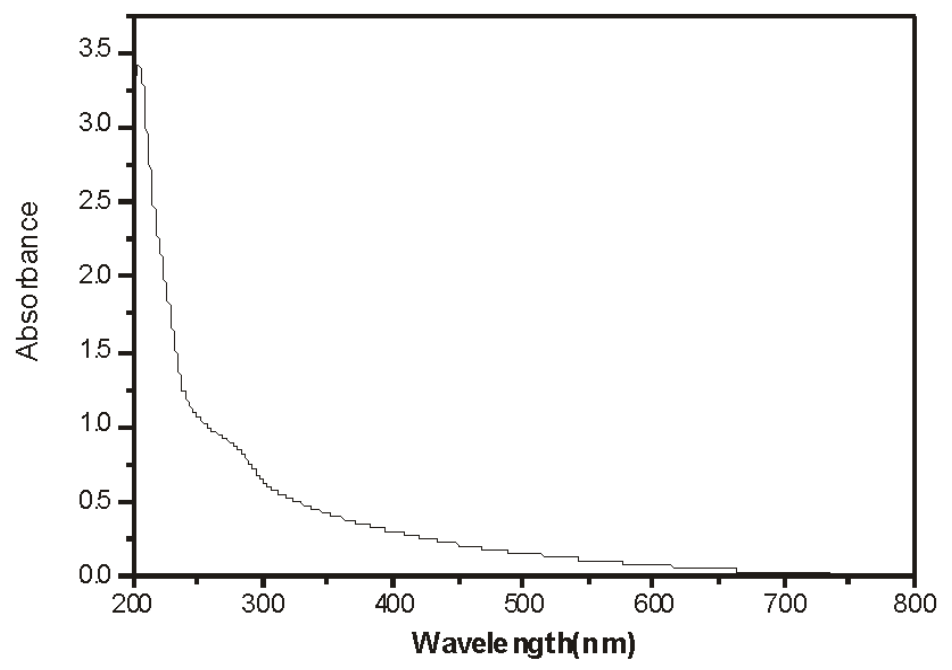

Figure 4 : Ultra Violet spectrum of Normal child 


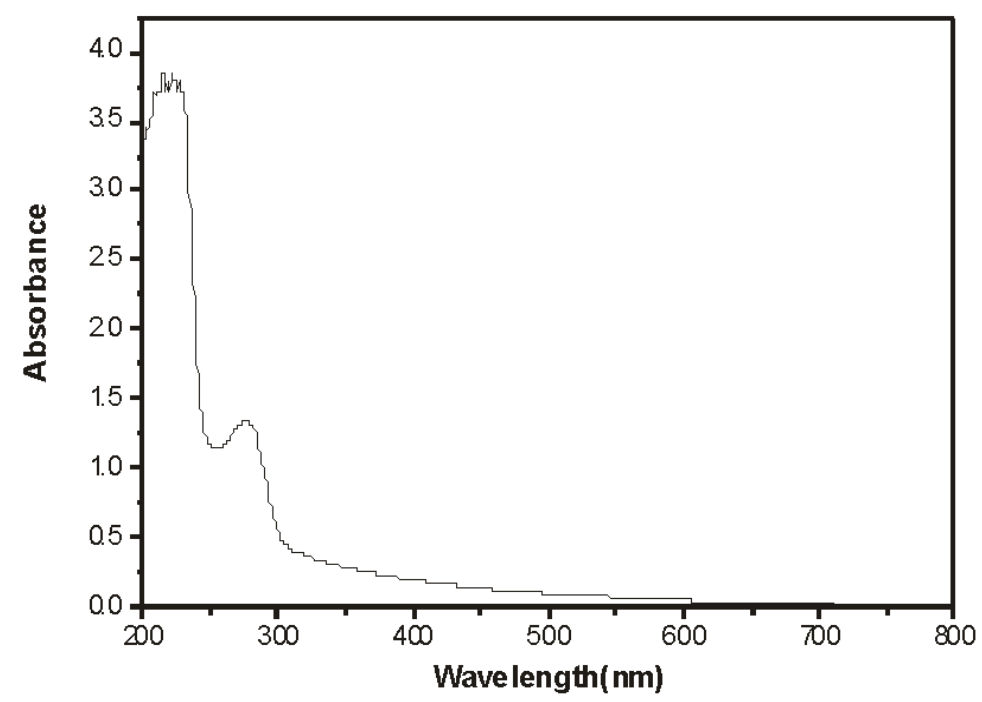

Figure 5 : Ultra Violet spectrum of DMD Child

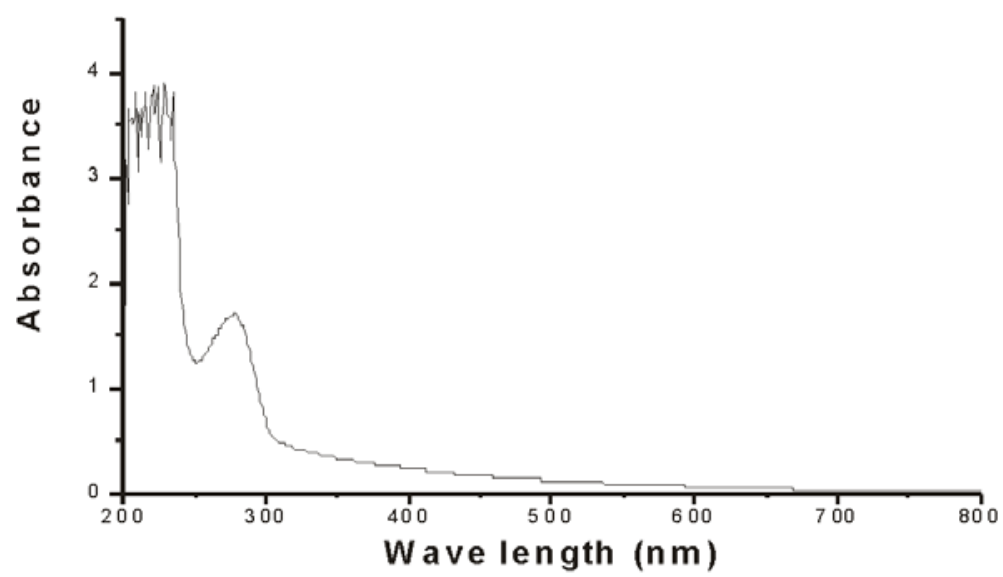

Figure 6 : Ultra Violet spectrum of Alzheimer's diseased person

Table. 1: Experimental findings on the immunoglobulin G molecule of Alzheimer's disease patients and healthy controls and compared with epileptic samples.

E-Epilepsy N-Normals and GME-Grand Mal Epilepsy, AD- Alzheimer's disease, NAD Controls for Alzheimer's. DMD- Duchenne Muscular Dystrophy , NDMD -Controls for DMD

\begin{tabular}{|c|c|c|c|c|c|}
\hline S.No. & $\begin{array}{l}\text { Type of } \\
\text { sample }\end{array}$ & Peak 1 nm. & Peak 2 nm. & Peak $3 \mathrm{~nm}$. & References \\
\hline 1 & $\mathrm{~N}$ & 205.80 & 243.08 & 299.96 & \multirow{7}{*}{ Kumar [33] } \\
\hline 2 & $\mathrm{~N}$ & 208.32 & 232.97 & 275.95 & \\
\hline 3 & $\mathrm{~N}$ & 205.6 & 260.6 & 278.6 & \\
\hline 4 & $\mathrm{~N}$ & 206.6 & 260.4 & 277.8 & \\
\hline 5 & $\mathrm{~N}$ & 207.2 & 243.2 & 279.2 & \\
\hline 6 & $\mathrm{~N}$ & 208.1 & 244.1 & 280.1 & \\
\hline 7 & $\mathrm{~N}$ & 206.0 & 244.1 & 281.0 & \\
\hline
\end{tabular}




\begin{tabular}{|c|c|c|c|c|c|}
\hline 8 & $N$ & 207.8 & 246.8 & 280.8 & \\
\hline 9 & $\mathrm{~N}$ & 203.6 & 243.2 & 276.6 & \\
\hline 10 & $\mathrm{~N}$ & 207.2 & 241.4 & 284.6 & \\
\hline 11 & $N$ & 205.4 & 244.1 & 282.8 & \\
\hline 12 & $\mathrm{~N}$ & 207.4 & 230.44 & 278.48 & \\
\hline 13 & GME & 205.8 & 260.8 & 278.8 & \\
\hline 14 & GME & 205.8 & 268.4 & 283.4 & \\
\hline 15 & GME & 205.2 & 259.8 & 278.6 & \\
\hline 16 & GME & 205.2 & 260.8 & 278.4 & \\
\hline 17 & GME & 206.6 & 268.6 & 278.6 & \\
\hline 18 & GME & 205.8 & 260.4 & 278.6 & \\
\hline 19 & GME & 205.0 & 268.8 & 277.4 & \\
\hline 20 & GME & 205.8 & 260.8 & 278.8 & \\
\hline 21 & GME & 206.0 & 268.8 & 278.4 & \\
\hline 22 & GME & 205.4 & 261.0 & 278.6 & \\
\hline 23 & GME & 206.2 & 261.2 & 278.6 & \\
\hline 24 & GME & 205.6 & 261.0 & 278.4 & \\
\hline 25 & GME & 205.8 & 259.9 & 278.6 & \\
\hline 26 & $E$ & 207.71 & 237.41 & 279.13 & \\
\hline 27 & $E$ & 206.45 & 231.73 & 280.39 & \\
\hline 28 & $E$ & 202.45 & 231.73 & 280.03 & \\
\hline 29 & $E$ & 202.65 & 232.99 & 280.03 & \\
\hline 30 & $E$ & 202.65 & 234.25 & 281.02 & \\
\hline 31 & $E$ & 203.20 & 231.71 & 280.37 & \\
\hline 32 & $E$ & 200.01 & 231.61 & 278.38 & \multirow{7}{*}{ Kumar [33] } \\
\hline 33 & $E$ & 202.20 & 234.24 & 279.11 & \\
\hline 34 & $E$ & 202.40 & 235.50 & 279.74 & \\
\hline 35 & $E$ & 203.17 & 235.40 & 279.01 & \\
\hline 36 & $E$ & 201.27 & 235.40 & 279.01 & \\
\hline 37 & $E$ & 202.65 & 238.68 & 279.01 & \\
\hline 38 & $E$ & 202.65 & 238.05 & 279.01 & \\
\hline 39 & $A D$ & 232.92 & 276.65 & 335.05 & \multirow{11}{*}{ Present work } \\
\hline 40 & $A D$ & 229.20 & 269.35 & 305.58 & \\
\hline 41 & $A D$ & 229.20 & 270.00 & 298.55 & \\
\hline 42 & $A D$ & 225.55 & 267.16 & 305.85 & \\
\hline 43 & $A D$ & 228.47 & 269.35 & 313.15 & \\
\hline 44 & $A D$ & 229.20 & 267.16 & 313.15 & \\
\hline 45 & $A D$ & 225.55 & 273.00 & 308.77 & \\
\hline 46 & $A D$ & 235.77 & 269.35 & 298.55 & \\
\hline 47 & $A D$ & 222.63 & 244.53 & 274.46 & \\
\hline 48 & $A D$ & 225.55 & 268.62 & 301.47 & \\
\hline 49 & $A D$ & 221.90 & 278.89 & 296.36 & \\
\hline
\end{tabular}




\begin{tabular}{|c|c|c|c|c|c|}
\hline 50 & $A D$ & 224.82 & 262.05 & 300.01 & \multirow{29}{*}{ Present work } \\
\hline 51 & NAD & 230.66 & 270.08 & 306.58 & \\
\hline 52 & NAD & 228.47 & 267.89 & 303.66 & \\
\hline 53 & NAD & 235.77 & 268.62 & 318.99 & \\
\hline 54 & NAD & 230.66 & 267.16 & 311.69 & \\
\hline 55 & NAD & 228.47 & 270.00 & 297.82 & \\
\hline 56 & NAD & 221.17 & 260.59 & 301.47 & \\
\hline 57 & NAD & 224.82 & 271.54 & 297.82 & \\
\hline 58 & NAD & 228.47 & 272.27 & 305.12 & \\
\hline 59 & NAD & 235.77 & 267.16 & 301.47 & \\
\hline 60 & NAD & 228.47 & 272.27 & 303.66 & \\
\hline 61 & DMD & 222.22 & 275.85 & 311.92 & \\
\hline 62 & DMD & 222.20 & 277.70 & 303.60 & \\
\hline 63 & DMD & 220.35 & 273.63 & 311.00 & \\
\hline 64 & DMD & 204.14 & 255.50 & 296.20 & \\
\hline 65 & DMD & 211.10 & 259.20 & 307.30 & \\
\hline 66 & DMD & 212.58 & 264.38 & 308.78 & \\
\hline 67 & DMD & 227.38 & 281.40 & 325.80 & \\
\hline 68 & DMD & 200.00 & 244.40 & 286.95 & \\
\hline 69 & N DMD & 225.90 & 285.10 & 314.70 & \\
\hline 70 & N DMD & 225.90 & 297.70 & 307.30 & \\
\hline 71 & N DMD & 229.60 & 287.69 & 329.50 & \\
\hline 72 & N DMD & 200.00 & 245.51 & 302.86 & \\
\hline 73 & N DMD & 200.00 & 245.51 & 303.60 & \\
\hline 74 & N DMD & 200.00 & 249.58 & 296.20 & \\
\hline 75 & N DMD & 200.00 & 244.40 & 299.90 & \\
\hline 76 & N DMD & 221.83 & 281.40 & 318.40 & \\
\hline 77 & N DMD & 200.00 & 246.25 & 351.70 & \\
\hline 78 & N DMD & 220.35 & 279.55 & 309.15 & \\
\hline
\end{tabular}

We have found three types of bands in the spectra of IgG of DMD patients and normal healthy controls. First and second band regions cover the ultraviolet behavior of proteins but third band does not show absorbance of proteins because the absorbance intensity greater than $310 \mathrm{~nm}$. Third band does not contain protein without tryptophan. We have to concentrate on the region of two bands below 300nm. We have first region in the range $200 \mathrm{~nm}$. to $227.38 \mathrm{~nm}$. in DMD patients and $200 \mathrm{~nm}$. to $229.60 \mathrm{~nm}$. in normal controls .Second region starts from $244.40 \mathrm{~nm}$. to $297.70 \mathrm{~nm}$.in patients and $244.40 \mathrm{~nm}$. to $297.70 \mathrm{~nm}$. in controls only. Third band did not show any protein absorbance in all the cases of study. We have found Ist band ranges from $\left(221.17 \mathrm{~nm}^{-1}\right.$ to $\left.235.77 \mathrm{~nm}^{-1}\right)$ in all the cases of $A D$ and healthy subjects. 
The second band ranges from $\left(244.53 \mathrm{~nm}^{-1}\right.$ to $278.89 \mathrm{~nm}^{-1}$ ) in $A D$ and normal and available at $\left(260.59 \mathrm{~nm}^{-1}\right.$ to $\left.272.27 \mathrm{~nm}^{-1}\right)$. There is a variation between these two categories for this band region. There is a shift in the lower side of the band in AD cases. On the other hand a shift in the right side of the band is also observed.

The third band was found in the range from $\left(274.46 \mathrm{~nm}^{-1}\right.$ to $\left.313.55 \mathrm{~nm}^{-1}\right)$ in AD samples while in NAD it starts from $297.52 \mathrm{~nm}^{-1}$ to $318.99 \mathrm{~nm}^{-1}$. It has been seen that the variation in $A D$ samples is on the decreasing pattern in comparison with healthy controls.

The band near at $275 \mathrm{~nm}$ is due to tyrosine amino acid residues of protein. It has been established that this band corresponds to a $\pi \rightarrow \pi^{*}$ transition. The increase in absorptivity and the long wave shift of the spectrum of tyrosine with ionization of the phenolic hydrogen provides the basis for studying the hydrogen ion equilibria of tyrosyl groups in proteins.

A band at $258 \mathrm{~nm}$ is associated with phenylalanine amino acid residues of protein. The low intensity absorption peak centered slightly below $260 \mathrm{~nm}$ corresponds to a forbidden $\pi \rightarrow$ $\pi^{*}$ transition. Vibrational fine structure is found in the region. Aside from increased blurring of the fine structure on passing into successively more polar media, change of solvent effects little change in the general size, shape and location of the absorption envelope. Forbidden transition occurs due to coupling of the electronic transition with different molecular vibrations in a way which removes the symmetry of the barrier.

The band of phenylalanine is weak and it is obscured in proteins by much stronger tyrosine and tryptophan absorptions. Phenylanaline is occasionally visualized in protein spectra as ripples or we may say fine structure in the region $250 \mathrm{~nm}-270 \mathrm{~nm}$. These ripples can be amplified by the difference spectral method.

It is very important to point out that the absorptivity of phenylanaline is very small around $260 \mathrm{~nm}$. It is the strongest absorbers in the region of the peptide absorption.

The spectrum of tryptophan appears in the range $270 \mathrm{~nm}$ to $290 \mathrm{~nm}$. The absorptivity of tryptophan is greater than unionized tyrosine and about twice as great as ionized tyrosine.

\section{DISCUSSION}

The ultraviolet spectra of proteins have been made the subject of study. It has been well established that the spectra of amino acids show proteins have a high intensity absorption band in the neighborhood area of $190 \mathrm{~nm}$. A similar band is found in simple peptides, with absorptivity increasing with increasing chain length in oligopeptides. The band at $190 \mathrm{~nm}$ is not available with aliphatic amino acids.

It has been seen in several proteins the molar absorptivity per peptide bond at $205 \mathrm{~nm}$ falls in the range $260 \mathrm{~nm}$ to $310 \mathrm{~nm}$. This shows that a contribution of seventy percent of total 
absorptivity, the peptide absorptivity is conformation dependent. The absorption spectrum of proteins is of great interest and made easy to study.

A detailed study for absorbance on proteins was carried out by some scientist and is given in Table-2 (Rosenheck, K. et. al. [9]).

Table. 2: Comparison of different proteins.

\begin{tabular}{|c|c|c|c|c|c|}
\hline S.No. & Type of sample & $\begin{array}{ll}\text { Peak } 1 \\
\mathrm{~nm} .\end{array}$ & $\begin{array}{ll}\text { Peak } 2 \\
\text { nm. }\end{array}$ & $\begin{array}{ll}\text { Peak } 3 \\
\text { nm. }\end{array}$ & References \\
\hline 1 & Carbonic anhydrase & 280.0 & - & - & \\
\hline 2 & Carboxy peptidase A & 278.0 & - & - & Neurath [34] \\
\hline 3 & Chymotrypsinogen & 282.0 & - & - & Chervenka [35] \\
\hline 4 & $\alpha$-Lactalbumin & 280.0 & - & - & \\
\hline 5 & $\beta$-Lactoglobin & 280.0 & - & - & Gorden et. al. [36], Piezt [37] \\
\hline 6 & Lysozyme & 281.0 & - & - & $\begin{array}{l}\text { Formageot et. al. [38], } \\
\text { Wetlauferet. al. [39] }\end{array}$ \\
\hline 7 & Papain & 278.0 & - & - & Glazer et. al. [40] \\
\hline 8 & Ribonuclease & 277.5 & - & - & Hermans et. al. [41] \\
\hline 9 & $\begin{array}{ll}\text { Bovine } & \text { serum } \\
\text { mercaptalbumin } & \end{array}$ & 280.0 & - & - & \\
\hline 10 & $\begin{array}{l}\text { Human serum } \\
\text { mercaptalbumin }\end{array}$ & 279.0 & - & - & \\
\hline 11 & $\begin{array}{l}\Delta \text {-3-Ketosteroid } \\
\text { isomerase }\end{array}$ & 277.0 & - & - & Kawahara et.al. [42] \\
\hline \multirow{2}{*}{12} & \multirow{2}{*}{ Tryptophan } & 267.2 & 274.7 & 281.6 & \multirow{6}{*}{$\begin{array}{l}\text { Coulter et. al. [43], } \\
\text { William et. al. [44] }\end{array}$} \\
\hline & & & 275.0 & & \\
\hline \multirow{2}{*}{13} & \multirow{2}{*}{ Tryptophan } & 269.4 & 279.4 & 288.8 & \\
\hline & & & 278.9 & 287.5 & \\
\hline \multirow{2}{*}{14} & \multirow{2}{*}{ Phenylalanine } & 271.4 & - & - & \\
\hline & & 263.3 & 257.6 & 251.6 & \\
\hline 15 & Tryptophan & 280.0 & - & - & \multirow{3}{*}{ Franz [45] } \\
\hline 16 & Tyrosine & 275.0 & - & - & \\
\hline 17 & Phenylalanine & 258.0 & - & - & \\
\hline
\end{tabular}

There is a broad band with a peak found in the spectrum of protein at $280 \mathrm{~nm}$ and a minimum at about $250 \mathrm{~nm}$ on the shorter wave length side. This band may be correlated with the presence of tyrosine tryptophan and phenylalanine [46]. The absorption band which is found at wave length above $280 \mathrm{~nm}$ is due to non protein occur chromophore. Nucleo proteins 
shows maximum in the region of $260 \mathrm{~nm}$. This may be associated with the presence of purine and pyrimidine nuclei. Bovine serum albumin (BSA) shows two characteristics UV bands around $280 \mathrm{~nm}$ and $215 \mathrm{~nm}$ respectively.

Some of spectra reported for proteins end at $235 \mathrm{~nm}$ on the shorter wavelength side of the main $280 \mathrm{~nm}$ peak. The absorption curves rise rapidly in this region. Steep rise may provide some information regarding the region of continuous absorption. Specific structure of a protein distinguish it from other compounds in the presence of a large number of peptide bands. UV spectra of anhydrides, esters and fatty acids and acid chloride show a broad band in the region of $200 \mathrm{~nm}$. Ultra violet spectroscopic studies below $240 \mathrm{~nm}$ are of interest. Ultra violet spectroscopic studies of amino acids were also carried out by Coulteret. al. [43] and they have reported that aliphatic amino acids do not show absorption above $250 \mathrm{~nm}$. Tyrosine tryptophan and phenylalanine show spectrum of absorption in the same spectral region as the proteins. The ultra violet absorption band of proteins has in consequence been attributed to the content of amino acids.

It has been seen that the peptide group of the protein main chain absorb the light energy in the range from $180 \mathrm{~nm}$ to $230 \mathrm{~nm}$. Aromatic side chains of tryptophan tyrosine and phenylalanine also absorb light in this region. These residues of proteins may absorb light in the region from $240 \mathrm{~nm}$ to $300 \mathrm{~nm}$. Disulfide bond also shows a absorption character near to 260 $\mathrm{nm}$. The aromatic amino acids do not absorb any light above $310 \mathrm{~nm}$. The protein absorbance above $310 \mathrm{~nm}$ is zero. The proteins without tryptophan residues do not show any absorption spectrum above $300 \mathrm{~nm}$.

There is a region which starts from $285 \mathrm{~nm}$ to $295 \mathrm{~nm}$ shows several bands which originate from the nine tyrosine and the single tryptophan residue.

We would like to make a point of inference that at $205 \mathrm{~nm}$ the side chains of amino acids make relatively small contribution to the total absorption of proteins and it is absent in all $A D$ and normal subjects.

Absorption coefficient for the peptide bond is of an order of magnitude many times higher than that of amide or carboxylic group. It can be said that the side chain of amino acids.

Our data did not support the work of Scopes [5]. Tyrosine absorbance at $205 \mathrm{~nm}$ is a fundamental property of the proteins but we could not get any absorbance at this level. It might be due to the aging factor of the human subjects in our study. The diet has also play an important key role in the metabolism of the body. If we take diet in rich proteins and other compounds then there is a possibility to have such types of absorbance due to tyrosine. It might be the change due to some other factors of the body. Our main aim was to throw light on the molecular level of immunoglobulin $\mathrm{G}$ molecule of proteins. We have also succeeded in giving our views related to ultraviolet spectroscopy. Now days ultraviolet spectroscopic studies are not 
in bulk but few studies are also available at the present period of research. One research group of this ultraviolet activity is engaged in determining all the biological fluids such as plasma, hemoglobin, CSF, urine etc. to give a definite contribution to the total absorption of proteins. It can be taken into consideration for the study of conformation of structure of proteins [47].

Franz [45] studied the ultra violet spectroscopic behavior of biological molecules and supplied suitable information for the general character of proteins such as detection of conformational changes and ligand binding etc.

On the basis of presence finding we can safely said that the tryptophan content is a good parameter for the conformation of structure of IgG.

\section{CONCLUSION}

Proteins and nucleic acids are supposed to be linear polymers [48]. It has been seen that in the polymers a limited set of residues are bound together with the help of amide or phosphodiester bonds. We have a situation like carbohydrates bound through the linking options.

The UV absorbance spectrum for a biomolecule is sum of the spectra of component parts. The UV absorbance for nucleic acids is found from $200 \mathrm{~nm}$ to $300 \mathrm{~nm}$. This spectrum is due to transitions of the purine and pyrimidine bases.

The backbone starts to contribute at about $190 \mathrm{~nm}$. The region, which is accessible and required below $200 \mathrm{~nm}$. It is found to be dominated by

$A \rightarrow A^{*}$ transition of the bases. Oxygen absorption interferes with the spectrum. The UV spectra of the bases look like simple bands. Each band is a composite of more than one transition.

The base transitions are disturbed significantly by $\pi \rightarrow \pi$ stacking interactions. The wavelength maxima and transition intensities vary depending on the base sequence and structure.

In the case of peptides and proteins the spectroscopy of amide bands, the side chains and any prosthetic group determines the observed UV-visible absorption spectrum. The intensities and wavelengths for nucleic acids can be disturbed by the local environment of the groups. UV spectra for proteins can be divided into two regions like near and far UV region. The near UV zone is started from $250 \mathrm{~nm}$ to $300 \mathrm{~nm}$ and is also described as the aromatic region. Transition of disulphide bonds also contribute to the total absorption intensity in the said region. The far UV above $250 \mathrm{~nm}$ is directly dominated by the transition of the peptide backbone of the protein, but transitions from some side chains may also contribute to the spectrum below $250 \mathrm{~nm}$. 
The aromatic side chain, phenylanaline, tyrosine and tryptophan all have transition in the near UV region.

Tryptophans have most intense transitions. Many proteins have few tryptophans compared with the other aromatic groups. These transitions are not dominated in the near ultraviolet regions.

The peptide chromophore gives transitions in the region from $180 \mathrm{~nm}$ to $240 \mathrm{~nm}$. It has non bonding electrons on the oxygen and also on the nitrogen atoms. This chromophore has $\pi-$ electrons which are delocalized to some extent over the carbon, oxygen and nitrogen atoms. This peptide chromophore has the transitions of $\sigma$ bonding electrons. The lowest energy transition of the peptide chromophore is a $\pi \rightarrow \pi^{*}$ transition. This transition is analogous to ketones.

The $\pi \rightarrow \pi^{*}$ transition is dominated by the carbonyl $\pi$-bond. This bond is also affected by the involvement of the nitrogen in the $\pi$-orbitals. The electric dipole transition moment is also polarized some where near the line between the oxygen and nitrogen atoms. This transition has a centre at $190 \mathrm{~nm}$. It has been seen that in an $\alpha$-helix, the coupling of the $\pi \rightarrow \pi^{*}$ transition moments in each amide chromophore results a component at about $208 \mathrm{~nm}$, which contribute to the characteristic $\alpha$-helix.

Protein absorbances can be seen as dominated by tryptophan residues and a clear out absorbance found at $280 \mathrm{~nm}$. The other aromatic residues also absorb at $280 \mathrm{~nm}$. This absorbance may be used to give an estimate of protein concentrations. It has been experimentally verified and checked by the researchers that $1 \mathrm{mg} \mathrm{cm}^{-3}$ protein solution has an absorbance of 1 absorbance unit in a $1 \mathrm{~cm}$ path length cell. This is due to the fact that many proteins have a similar percentage of aromatic amino acid residues.

The Bear-Lambert law for the determination of concentration of nucleic acids and proteins is based on the fact that the samples are hundred percent pure. If nucleic acids are found, the interference of these with the protein concentration determination may appear. They also absorb at $280 \mathrm{~nm}$.

Phenylalanine residues contribute fine structure such as wiggles to the spectrum from $250 \mathrm{~nm}$ to $260 \mathrm{~nm}$. The aromatic amino acids do not absorb above $310 \mathrm{~nm}$. Neither proteins nor nucleic acids ultraviolet absorbance at $320 \mathrm{~nm}$. It has been well documented that protein absorbance should be zero at wavelengths greater than $310 \mathrm{~nm}$. Proteins without tryptophan residues do not absorb above $300 \mathrm{~nm}$.

The studies of peptides are suggestive consideration of protein structure. Electrostatic effects are very small. The peptide absorption coefficients for a protein should depend on the amino acid composition. It should be greater than triglycine. 
We conclude this method is reliable and efficient to detect the changes at the molecular level. Specific changes could be seen in the structure of protein molecule with the help of detailed theory of ultraviolet spectroscopy. This spectroscopy confirms that the absorbance by proteins above $300 \mathrm{~nm}$ is not possible and no protein absorb at this wavelength. We have found the absorbance peaks above this wavelength. Other spectroscopic techniques may help in the study of this absorbance. The ultraviolet spectroscopy is reliable and usable technique and more predictive related to protein determination.

Our study shows a clear cut indication regarding protein absorbance that the proteins are damaged in the region of third band completely. We have to study more to get the cause of the non-availability of absorbance of proteins by other suitable method of spectroscopy.

\section{ACKNOWLEDGEMENT}

The authors are thankful to Dr. P. K. Saxena, Principal, D.A.V. (P.G.) College, Muzaffarnagar for providing the facility of doing work. We are also thankful to Professor D. C. Jain, Head of the Department of Neurology, Safdarganj Hospital, New Delhi, for arranging the blood samples of the diseased and healthy controls. We are thankful to Dr. Manju Chauhan, Head, Department of Biosciences, D.A.V. (P.G.) College, Muzaffarnagar, for providing the facility of purification of IgG.

\section{REFERENCES}

[1]. Brennan, N. F, UV/VIS Spectroscopy. University of Pretoria, etd. 2006. :p. 109- 121.

[2]. Pavia, D. L., G. M. Lampman and G. S. Kritz, Introduction to Spectroscopy, A Guide for Students of Organic Chemistry, $3^{\text {rd }}$ edition. Brooks/Cole. Thomson Learning . Australia, U.S.A. 2011. :p. 267- 293.

[3]. Lambert, J.H., Photometria, Sive De Mensura Et Gradibus Luminis, Colorum et Umbrae. Deutsch. heraugegeben. Von. Anding, E. Zweites, Heft. Theil III, IV und V Mit 32 Figurem im Text Leipzig, Verlag Von. Wilhelm Engelmann 1892. 1760 :p. 1-135.

[4]. Mulliken, R. A, Intensities of Electronic Transition in Molecular Spetra I : Introduction. J. Chem. Phys, 1939.79(1) : p. 14-20.

[5]. Scopes, R. K, Measurement of Protein by Spectrophotometry at $205 \mathrm{~nm}$.. Analytical Biochem,1974 .59 : p. 277-282.

[6]. Jagger, J, Conduct of Experiments. In : Introduction to Research in Ultraviolet Photobiology, Printice Hall, Inc. Englewood. N. J. Cliffs, 1967. p. 50-67.

[7]. Perkampus, H. H, Band Analysis, In: UV-VIS Spectroscopy and its Applications translated by G. H. Charlotte, and T. L.Therelfall, Springer Verlag, Berlin, 1992 . :p. 220-34.

[8]. Haschemeyer, R. H. and A. F. V. Haschemeyer, In: Proteins, John Wiley, New York, 1973. :p .219-220. 
[9]. Rosenheck, K and P. Doty, The Far Ultraviolet Absorption Spectra of Polypeptides and Protein Solutions and their Dependence on Conformation. Proc. Nat. Acad. Sci. Wash, 1961. 47 : p. 1775-1785.

[10]. Glazer, A. N. and E. L. Smith, Effect of Denaturation on the Ultraviolet-Absorption Spectra of Proteins. J. Biol. Chem , 1960. :235, P.C. 43.

[11]. Glazer, A. N. and E. L. Smith, Studies on the Ultraviolet Difference Spectra of Proteins and Polypeptides. J. Biol. Chem, 1961. 236 : p. 2942-2947.

[12]. Jiang, J., D. Abramavicius, M. B. Benjamin, D. H. Jonathan and S. Mukamel, Ultraviolet Spectroscopy of Protein Backbone Transition in Aqueous Solution: Combined QM and MM Simulations. J. Phys. Chem, 2010. B114(24) : p. 8270-8277.

[13]. Amoldus, W. P. and W. Norde, The Thermal Stability of Immunoglobulin : Unfolding and Aggregation of a Multidomain Protein. Biophysical. Journal, 2000. 78 : p. 394-404.

[14]. Motrescu, I., S. Oancea, A. Rapa and A. Airinei, Spectrophotometric Analysis of the Blood Plasma for Different Mammals. Romanian J. Biophys, 2006.16 (3) : p. 215-220.

[15]. Kanagathara, N., M. Thiruvanukkarasu, J. C. Esther and P. Shenabagarajan, FTIR and UV-Visible Spectral Study on Normal Blood Samples, I.J.P.B.S, 2011. 1( 2) : p. 74-81.

[16]. Gunasekaran, S. and D. Uthra, FTIR and UV-Visible Spectral Study on Normal and Jaundice Blood Samples.Asian J. Chemistry, 2008. 20( 7) : p. 5695-5703.

[17]. Yuette, M. D., G. R. Mitrani, S. Orton, C. P. Bacon, G. Leparc, M. Bayona, R. Potter and G. R. H. Luis, Blood Characterization using UV/VIS Spectroscopy, In: Advances in Fluorescence Sensing Technology II, R. L., Joseph,Editor Proc. SPIE, 1995. 2388 : p. 462-470.

[18]. Yuette, M. D., G. Leparc, R. Potter, G. R. H. Luis, Multi wavelength UV/Visible Spectroscopy for the Quantitative Investigation of Platelet Quality, Optical Biopsy II, R. A. Rober, Editor, Proc. SPIE, 1998. 3250 : p. 101-109.

[19]. Akihisa, N., Using Multiwavelength UV-Visible Spectroscopy for the Characterization of Red Blood Cells: An Investigation of Hypochromatism, Ph. D. Thesis, University of South Florida, ISBN 9780496894444, Dissertation Abstracts International, 1998. 2004. 65-12(Section B) : p. 6370.

[20]. Wilhelm, S. and R. Melvin, Ultra-Violet Absorption Spectra of Blood Serum and Certain Amino Acids.J. Biol. Chem, 1925.66 : p. 819-827.

[21]. Melvin, R. C, Ultraviolet Absorption Spectra of Certain Physiological Fluids. J. Gen. Physiol,1927. $11:$ p.1-6.

[22]. Edward, P. A. and C. B. Charles, The Middle Ultraviolet Spectra of Proteins I. Studies On Model Compounds. Can. J. Bioch. 1970. 48(9) : p. 953- 961.

[23]. Calvin, B., M. S. Florence and A. K. Elvin, The Structure of the Ultraviolet Absorption Spectra of certain Proteins and Amino Acids. The Journal of General Physiology, 1936. 19( 5) : p.739-752. 
[24]. Alastair, A and L. Michele, Protein Determination by UV-Absorption, In : The Protein Protocols Handbook, J. M.Walker, Editor, Humanna Press, New Jearsy, 1996 : pp 3-6, DOI : 10.1007/978-1-60327-259-91.

[25]. Yong, S. C., B. S. Kyung and Y. Koji, Effect of Ultraviolet Irradiation on Molecular Properties and Immunoglobulin Production-Regular Activity of B-lacoglobulin.Food. Sci. Biotechnol, 2010. 19( 3) : p. $595-602$.

[26]. Henryk, M., S. Gautam, B. V. David and M. C Russel, Application of Ultraviolet Absorption Spectroscopy to the Analysis of Biopharmaceuticals. In: Therapeutic Protein and Peptide Formation and Delivery. Am. Chem. Society ACS Symposium Series. 1997. 675 : p.186-205, ISBN 13: 978084123528,

[27]. Mc Carthy, D. A. and A. F. Drake, Spectroscopic Studies on IgG Aggregate Formation. Mol. Inmunol, 1989. 26( 9) : p. 875-881.

[28]. Edelhoch, H, Spectroscopic Determination of Tryptophan and Tyrosine in Proteins.Biochemistry, 1967.6 (7) : p. 948-54.

[29]. Mansur, H., R. Orefice, M. Pereira, Z. Labato, V. Wander and M. Lucas, FTIR and UV-VIS Study of Chemically Enginered Biomaterial Surfaces for Protein Immobilization. Spectroscopy, 2002. 16( 3-4) : p. 351-360.

[30]. Miriam, A., N. Toshihiko, I. Hideyuki and Y. Tatsuhio, Spectroscopic Studies of Hemes in Electron Carrier $\quad$ C-type Cytochromes and its Model Compounds. J. Photopolymer. Sci. \& Tech, 1998. 11(1) : p.139142.

[31]. Sanii, L., El-Sayed and A. Mustafa, Light-Dark Adaption and Trapping of the Deprotonated Schift Base in Buicelle Bacterio- Rhodospin Crystals Studied by Visible and Raman Spectroscopy, In: Partial Dehydration of the Retinal Binding Pocket and Proof for Photo-Chemical Deprotonation of the Retinal Schiff Base in Bicelle Bacteriorhadospin Crystals. Photochemistry and Photobiology, ASAP, 2005 : p. 83-84.

[32]. Hudson, L and F. C. Hay, Practical Immunology, $2^{\text {nd }}$ Edition, Black Well Scientific Publication, Oxford, London, Edinburg, Boston, Melbourne, 1980 : pp. 222.

[33]. Kumar, S., Medico -Physical Studies on Epilepsy and Other Neurological Disorders, Ph. D Thesis ,University of Delhi, India. 1989.

[34]. Neurath, H., In "The enzymes".P. D. Boyer, H. A. Lardyand, K. Myrback, $2^{\text {nd }}$ edition. Academic Press, New York. 1960. 4 : pp. 447-460,

[35]. Chervenka, C. H, The Urea Denaturation of Chymotrypsinogen and Determined by Ultraviolet Spectral Changes, Evaluation of Additional Kinetic Constants 1. J. Am. Chem. Soc, 1961. 83(2): p. 473-476.

[36]. Gordan, W. G., J. J. Basch and E. B. Kalan, Amino Acid Composition of Beta-Lactoglobulins A, B and $A B$, J. Biol. Chem., 1961. 236, : p. 2908-2911.

[37]. Piez, K. A., E. W. Davie, J. E. Folk and J. A. Gladner, B-Lactoglobulins A and B I Chromatographic Separation and Amino Acid Composition. J. Biol. Chem, 1961 , 236 : p. 2912-2916. 
[38]. Formageot, C. and G. Schnek, Lespectre Ultraviolet Dulysozyme : Avecdes Considerations Surle Spectre Ultraviolet de Divers Acids Amines Et De Quelques-uns De Leurs Peptides.Biochim. Et. Biophys. Acta, 1950. 6 : p. 113-122.

[39]. Wetlaufer, D. B. and M. A. Stahmann, Formation of Three-Dimensional Structure in Protein.J. Am. Chem. Soc, 1958.80 : p. 1493-1496.

[40]. Glazer, A. N. and E. I. Smith, Phenolic Hydroxyl Ionization in Papain.J. Mol. Chem., 1961 ,236 : p. 2948-2951.

[41]. Hermans, J. Jr., and N. A. Scherga, Structural Abnormal Ionizable Ural Studies of Ribonuclease V groups 1-3. J. Am. Chem. Soc, 1961. 83(15) : p. 3293-3300.

[42]. Kawahara, F. S., S. F. Wang and P. Jalalay, The Preparation and Properties of Crystalline $A^{5}$ Ketonsteroid Isomerase. J. Biol. Chem, 1962237, 1500-1506.

[43]. Coulter, C. B., F. M. Stone, and E. A. Kabat, The Structure of the Ultraviolet Absorption Spectra of Certain Proteins and Amino Acids. The Journal .General. Physiology. 1935. 19(5) : p. 739-752.

[44]. William, Wand S. Gavin, Protein Purification.Current Analytical Chemistry, 2009. 5(2): p. 1-21.

[45]. Franz, X. S., Biological Macromolecules : UV-visible Spectrophotometry. Encyclopedia of life sciences, Macmillan Publishing Group/www. els. net. 2001.

[46]. Morton, R. A., The Application of Absorption Spectra to the Study of Vitamins, Hormones and Enzymes, London, $2^{\text {nd }}$ edition, 1942 : p. 181-185.

[47]. Goldfarb, A. R., L. J. Saidel and E. Mosovich, The Ultraviolet Absorption Spectra of Proteins, J. Biol. Chemistry, 1951..193( 1 ): p. 397-404.

[48]. Rodger, A. and K. Sanders, Biomolecular applications of UV-visible absorption spectroscopy. Encyclopedia of Spectroscopy and Spectrometry, Edited by Tranter, G. E. and Holmes, J. L., 2000 : p.130-139. 